P. Miluski*, M. Kochanowicz, J. Zmojda, A.P. Silva, P.N.B. Reis, T. Ragin, and D. Dorosz

\title{
UV sensing optode for composite materials environment monitoring
}

https://doi.org/10.1515/secm-2019-0008

Received February 28, 2018; accepted January 26, 2019

Abstract: The polymeric optical fibre technology can be successfully used for UV spectrum range radiation measurements. A new type of fluorescent optical fibre optode is presented. The used fluorescent wave-shifter was used for UV-VIS conversion and radiation measurements. The linear characteristic with sensitivity $480 \mathrm{~mW}^{-1}$ is presented for UV range 7.2-13.6 $\mathrm{mW}$. Presented optode construction advantages (small dimensions, low weight, high immunity to electromagnetic fields and distributed sensor architecture possibility) are attractive for numerous composite based engineering applications.

Keywords: composite materials, CFRP, optical fibre sensor, fluorescence, polymeric optical fibre, poly(methyl methacrylate), 1,4-Bis(2-methylstyryl)benzene

\section{Introduction}

Advantages of polymer matrix based composite materials (flexibility, light weight, and high stiffness) are desired in numerous aerospace, automotive, marine and military applications [1-5]. Weight reduction and superior fatigue behaviour are the main reasons to move to composites materials in transportation technology [6]. Growing interest of composites for aircraft, satellites, spaceships, and rockets require stricter monitoring standards for manufacturing and working conditions [7-10]. There are several mechanisms of degradation of mechanical properties of composite elements (fibres breaking, matrix cracking, debonding, delamination and transverse-ply crack-

\footnotetext{
${ }^{\star}$ Corresponding Author: P. Miluski: University, 1Bialystok University of Technology, Faculty of Electrical Engineering, Bialystok, Poland, E-mail: p.miluski@pb.edu.pl

M. Kochanowicz, J. Zmojda: University, 1Bialystok University of Technology, Faculty of Electrical Engineering, Bialystok, Poland A.P. Silva, P.N.B. Reis: C-MAST, University of Beira Interior, Department of Electromechanical Engineering, Covilha, Portugal

T. Ragin: University, 1Bialystok University of Technology, Faculty of Mechanical Engineering, Bialystok, Poland

D. Dorosz: AGH University of Science and Technology, Krakow, Poland
}

ing). The stability of mechanical properties of composite materials depends on the combinations of numerous environmental and service conditions. The most important are: maximum static load, vibrations (fatigue parameters), temperature, moisture, ultraviolet, chemically aggressive environment [11-19]. The monitoring of such parameters is critical especially for testing new materials. Most of them can be monitoring by incorporation sensing structures (electrical or optical) inside of the composite structure. The metallic components damages are typically observed in the form of cracks or corrosion on the surface in opposite to composite materials where the degradation of mechanical properties can be caused by its inner structure defects and is invisible on the element surface. However, the polymeric matrix based composites properties (including moisture resistivity) change after long-term exposition to UV radiation. In general, the solar spectrum at the earth's surface contains between 280 and $2500 \mathrm{~nm}$. However, the spectrum of solar radiation significantly differs vs. altitude (atmosphere attenuation and clouds scattering effect). The much higher content of UV and VIS spectrum $(280-800 \mathrm{~nm})$ is noticeable near to the atmosphere edge [20-23]. Moreover, solar radiation reflected back from the clouds significantly change the UV irradiation at high-altitude. The UV-A and UVB range photons (wavelength $280-400 \mathrm{~nm}$ ) absorbed by polymers result in photo-oxidative reactions. The photoinduced of polymer structures changes (molecular chain scission and crosslinking) is possible due to comparable energies of UV photons to the dissociation energies of covalent bonds [24]. These effects can be minimized by modifying the polymer structures by photostabilizing agents. However, the effect of long-term exposition to UV radiation can't be omitted for aerospace applications. In such circumstances, the UV sensing elements which can be applied in an aerospace environment is crucial for safety aspects of using composite materials. The optical fibre technology is often used for structural health monitoring of composite materials. Well known optical phenomena (optical radiation scattering, Bragg grating reflectivity, micro and macro-bend losses) can be used for mechanical behaviour monitoring [8, 25-28]. Additionally, luminescent optical fibres, embedded in the material structure, can be used for temperature monitoring [15]. Optical fibre con- 
structions offers some specific advantages over electrical sensors since they can operate in the wide temperatures range and high intensity of electromagnetic fields. Moreover, small dimensions and light weight are important for aerospace applications. One of the well-known possibility of UV detection is using wave-shifter complexes which allow conversion UV into the visible spectrum range and observed with the bare eye. Additionally, VIS spectrum range sensitivity of typical silicon $\mathrm{p}$-n photodiodes is significantly higher than observed for UV wavelengths. High optical aperture and flexibility of polymeric optical fibres make them a good candidate for UV sensing optode construction. There are reported numerous organic complexes with efficient fluorescence under UV excitation [29-31]. However, the excitation spectra of organic fluorophores are very wide and very often overlap visible spectrum range and significantly decrease selectivity of such optodes. One of the wave shifter used in scintillating technology is 1,4-Bis(2-methylstyryl)benzene (Bis-MSB) in liquid and rigid polymeric host. Proposed in the paper (BisMSB) doped poly(methyl methacrylate) (PMMA) optode offers well-defined excitation spectrum with sharp edge UV/VIS spectral range. Additionally, characteristic fluorescence spectrum shape can be used for a visible range of solar spectrum shape influence minimization.

\section{UV optode construction}

Organic dye doped fibre preform was fabricated using free radical polymerization process of Methyl Methacrylate (MMA). The Methyl Methacrylate and Benzoyl Peroxide (BP), were supplied by Sigma-Aldrich. Inhibitor of the monomer has been removed before polymerization process. The 1,4-Bis(2-methylstyryl)benzene $99 \%$ was purchased from TCI and used as received. The process was performed by $24 \mathrm{~h}$ (precisely controlled temperature profile $60-80^{\circ} \mathrm{C}$ ). No visible polymerization defects (intrusion, cracking or bubbles) were observed in the fabricated preform. The PMMA preform was then drawn into the fibre using computer controlled drawing tower. The 1,4Bis(2-methylstyryl)benzene doped PMMA bare fibre (BisMSB concentration $7 \cdot 10^{-4} \mathrm{~mol} / \mathrm{l}$, diameter $2.0 \mathrm{~mm}$ and $20 \mathrm{~mm}$ length) was attached to the commercial step index profile PMMA fibre with fluorinated polymer cladding ( $0.75 \mathrm{~mm}$ outer diameter, approx. attenuation $200 \mathrm{~dB} / \mathrm{km}$, $1.6 \mathrm{~m}$ length) by using dissolved by acetone PMMA. The Bis-MSB concentration was chosen to obtain efficient fluorescence under UV radiation. The resulted UV sensing optode is shown in Fig. 1.

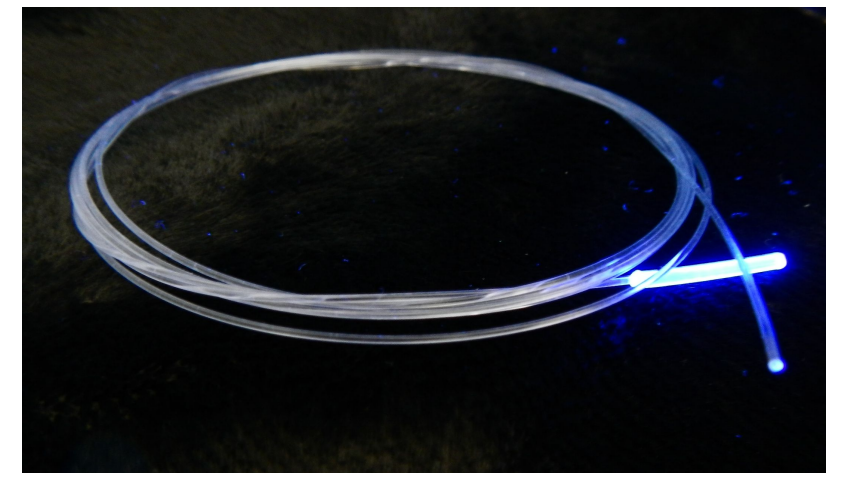

Figure 1: The manufactured UV sensing optode.

\section{Experimental procedure}

The excitation spectra of a bulk specimen of $2 \mathrm{~mm}$ thick slice of Bis-MSB doped PMMA preform was measured using xenon lamp (450 W) and fluorescence spectrometer (Horiba Fluorolog 3). Recorded excitation spectrum (Fig. 2) shows good uniformity (0.8-1.0) in the 300-400 $\mathrm{nm}$ range and overlaps the UV-A and UV-B solar radiation spectrum range.

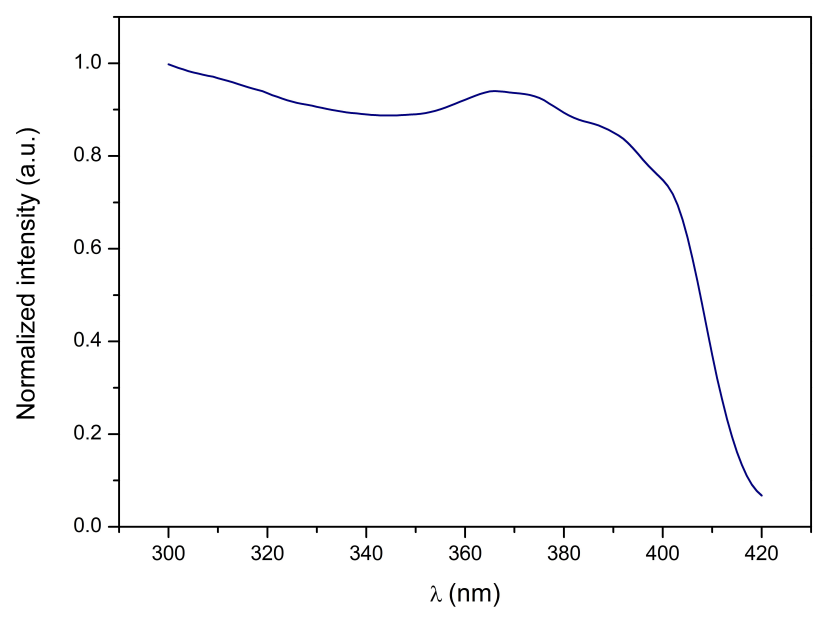

Figure 2: Excitation spectrum of Bis-MSB in PMMA (monitoring at $422 \mathrm{~nm})$.

The fluorescence signal (Fig. 3) was recorded using Stellarnet Green Wave spectrometer. The PM-100 optical power meter equipped with S121B silicone diode detector was used for laser diode power measurements. Optode characteristic (Fig. 4) was determined using laser diode MDL-III-397 nm (1-100 mW). Solar radiation (Fig. 5) was measured using photovoltaic digital multimeter Voltcraft PL-110SM. 


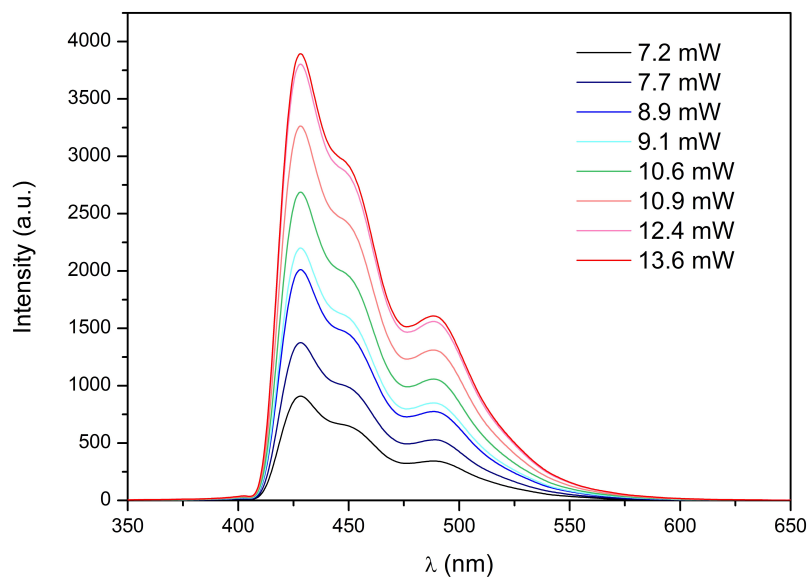

Figure 3: Fluorescence spectra of UV optode measured using 397 $\mathrm{nm}$ laser diode.

The evolution of fluorescence signal versus UV radiation range 7.2-13.6 $\mathrm{mW}$ was obtained by a linear function fitting with a correlation coefficient (Ra, adjusted $r$-square value) of 0.955 .

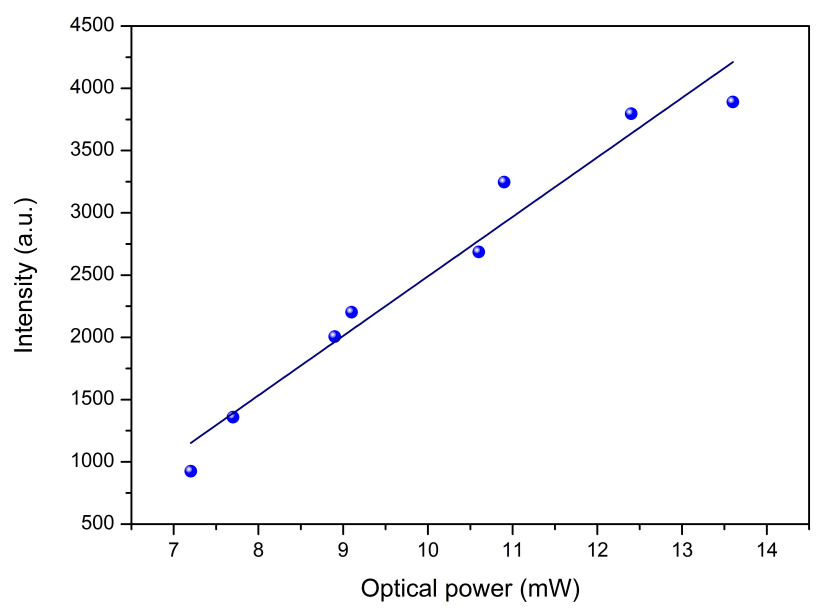

Figure 4: Maximum fluorescence intensity vs. UV radiation power.

The UV sensitivity of the luminescence signal (S) can be defined by the equation:

$$
S=\left|\frac{\Delta I}{\Delta I U V}\right|
$$

where $\Delta \mathrm{I}$ represent the increment in terms of signal and $\triangle \mathrm{IUV}$ the increments of UV radiation. For the measured UV (at $397 \mathrm{~nm}$ ) range, an average sensitivity of slope $480 \mathrm{~mW}^{-1}$, was obtained. In fact, composite materials are very sensitive to environment conditions (humidity, temperature, UV). Therefore, proposed sensor can be used for UV exposition measurements the CFRP laminate based constructions, especially for high-level UV radia- tion. Moreover, obtained high sensitivity and response linearity is useful in numerous applications.

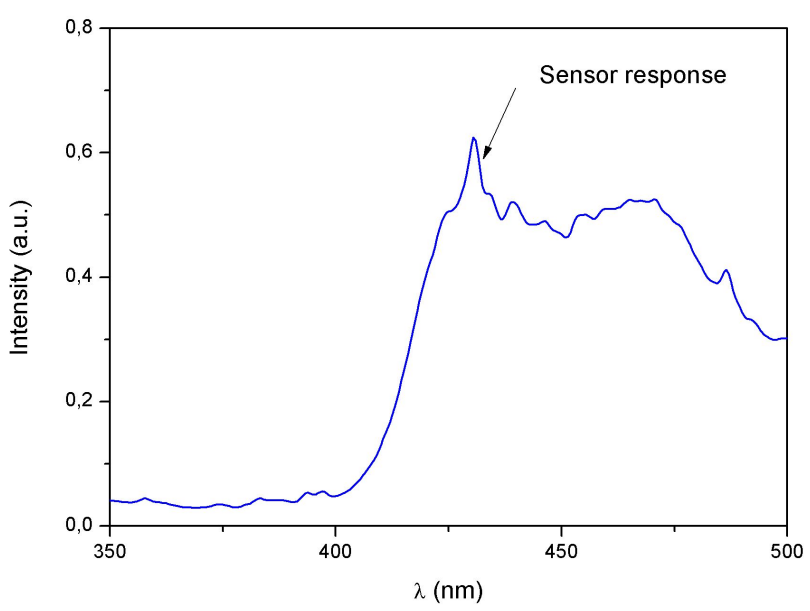

Figure 5: Measurements of UV under high solar radiation using proposed UV optode, solar irradiance $650 \mathrm{~W} / \mathrm{m}^{2}$.

High flexibility, low-cost production and easy coupling of numerous sensor to the single detector are attractive for array distributed sensor constructions as schematic presented in Fig. 6.

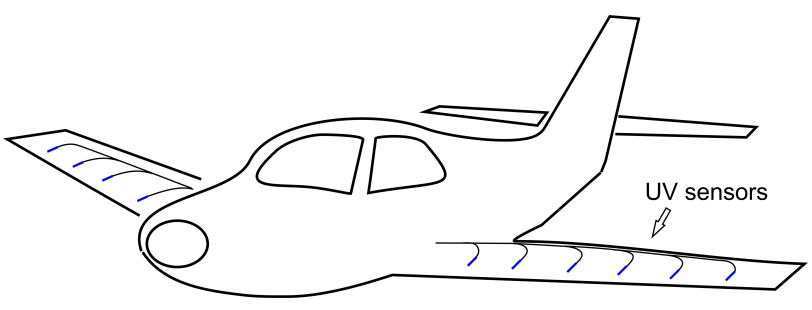

Figure 6: Aircraft UV sensor distributed system.

\section{Conclusions}

An optical fibre based UV sensor for composite materials environment monitoring was presented. The 1,4-Bis(2methylstyryl)benzene fluorescent wave-shifter was used for UV to VIS range conversion. The linear characteristic with sensitivity $480 \mathrm{~mW}^{-1}$ and $\mathrm{Ra}=0.955$ was presented for UV range $7.2-13.6 \mathrm{~mW}$. It is possible to conclude that linear UV optode function, small dimensions, flexibility are demanded by constructors of composite elements. Low weight, high immunity to electromagnetic fields and distributed sensor architecture are especially attractive for aircraft constructions. 
Acknowledgements: This work was supported by National Science Centre (Poland) project no. DEC2017/01/X/ST8/00595, and under EU COST Action MP1401 "Advanced fibre laser and coherent source as tools for society, manufacturing and life science".

\section{References}

[1] Koniuszewska A. G., Kaczmar J. W., Application of Polymer Based Composite Materials in Transportation, Progress in Rubber, Plastics and Recycling Technology, 2016, 32(1), 1-24.

[2] Campbell F.C., Structural composite materials, ASM International, 2010, ISBN-10: 0-61503-037-9.

[3] Thomas D. S., Gilbert S.W., Costs and cost effectiveness of additive manufacturing, National Institute of Standards and Technology, 2014, http://dx.doi.org/10.6028/NIST.SP.1176.

[4] Awalellu K. A., A review on properties and applications of polymer matrix composites, IJRSI, 2016, 3, 53-55.

[5] Nayak N. V., Composite materials in aerospace applications, International Journal of Scientific and Research Publications, 2014, 4(9), 1-10.

[6] Pervaiz M., Panthapulakkal S., Birat K. C., Sain M., Tjong J., Emerging trends in automotive lightweighting through novel composite materials, Materials Sciences and Applications, 2016, 7, 26-38.

[7] Konstantopoulos S., Fauster E., Schledjewski R., Monitoring the production of FRP composites: A review of in-line sensing methods, Express Polymer Letters, 2014, 8(11), 823-840.

[8] Di Sante R., Fibre optic sensors for structural health monitoring of aircraft composite structures: Recent advances and applications, Sensors 2015, 15, 18666-18713.

[9] Cenek S., Mudit R., Radek H., Structural health monitoring of composite structures using embedded PZT sensors in space application, European Conference Of The Prognostics And Health Management Society, 2014, 1-6.

[10] NASA Space Technology Roadmaps and Priorities: Restoring NASA's Technological Edge and Paving the Way for a New Era in Space, 2012, ISBN 978-0-309-25362-8.

[11] Cesari F., Dal Re V., Minak G., Zucchelli A., Damage and residual strength of laminated carbon-epoxy composite circular plates loaded at the centre, Composites A, 2007, 38, 1163-1173.

[12] Amaro A. M., Reis P. N. B., de Moura M. F. S. F., Residual strength after low velocity impact in carbon-epoxy laminates, Materials Science Forum, 2006, 514, 624-628.

[13] Amaro A. M., Reis P. N. B., Neto M. A., Cirne J. M., Residual impact strength of carbon/epoxy laminates after flexural loadings, Composite Structures, 2016, 146, 69-74.

[14] Silva J. M., Devezas T. C., Silva A. P., Ferreira J. A. M., Mechanical Characterization of Composites with Embedded Optical Fibers, Journal of Composite Materials, 2005, 39(14), 1261-1281.

[15] Miluski P, Kochanowicz M., Żmojda J., Silva A.P., P. N. B., Dorosz D., Carbon laminates with RE doped optical fibre sensors, Open Eng., 2016, 6, 385-388.

[16] Kumar B. G., Singh R. P., Nakamura T., Degradation of carbon fiber-reinforced epoxy composites by ultraviolet radiation and condensation, Journal of Composite Materials, 2002, 36(24), 2713-2733.
[17] Chhibber R., Environmental degradation of glass fibre reinforced polymer composite, UPWIND Integrated Wind Turbine Design, Project report, http://www.thapar.edu/images/research/ UpWind_Doc_final.pdf

[18] Feih S., Boiocchi E., Kandare E., Mathys Z., Gibson A. G., Mouritz A. P., Strength degradation of glass and carbon fibres at high temperature, Journal of Materials Science, 2009, 44(2), 392400.

[19] Jenkins P. G., Yang L., Liggat J. J., Thomason J. L., Investigation of the strength loss of glass fibre after thermal conditioning, Journal of Materials Science, 2015, 50(3), 1050-1057.

[20] Aglietti G. S., Redi S., Tatnall A. R., Markvart T., Harnessing highaltitude solar power, IEEE Transactions on Energy Conversion, 2009, 24(2), 442-451.

[21] Bachereau F., Marigo G., Asta J., Effect of solar radiation (UV and visible) at high altitude on CAM-cycling and phenolic compound biosynthesis in Sedum album, Physiologia Plantarum, 1998, 104(2), 203-210.

[22] McElroy C. T., A spectroradiometer for the measurement of direct and scattered solar irradiance from on-board the NASA ER-2 high-altitude research aircraft, TOC, 1995, 22(11), 1361-1364.

[23] Palancar G. G., Shetter R. E., Hall S. R., Toselli B. M., Madronich S., Ultraviolet actinic flux in clear and cloudy atmospheres: model calculations and aircraft-based measurements, Atmos. Chem. Phys., 2011, 11, 5457-5469.

[24] Kumar, B. G., Singh R. P, and Nakamura T., Degradation of carbon fiberreinforced epoxy composites by ulraviolet radiation and condensation, Jounal of Composite Matrerials, 2002, 36(24), 2713-33.

[25] Lee B., Review of the present status of optical fiber sensors, Optical Fiber Technology 2003, 9, 57-79.

[26] Rippert L., Papy J.-M., Wevers M., Van Huffel S., Fibre optic sensor for continuous health monitoring in CFRP composite materials, Proceedings of SPIE Vol. 4693, 2002, PIE · 0277-786X/02.

[27] Domański A.W., Bieda M., Lesiak P., woliński T. R., Polarimetric Optical Fiber Sensors for Dynamic Strain Measurement in Composite Materials, Acta Physica Polonica A, 2013, 124(3), 399401.

[28] Glisic B., Inaudi D., Development of method for in-service crack detection based on distributed fiber optic sensors, Structural Health Monitoring, 2011, 11(2), 161-171.

[29] Miluski P., Dorosz D., Kochanowicz M., Zmojda J., Optical fibre temperature sensor based on fluorescein and rhodamine codoped polymer layer, Proc. of SPIE, 2013, 8903, 89030C-6.

[30] Miluski P., Dorosz D., Zmojda J., Kochanowicz M., Dorosz J., Luminescent polymer optical fibre sensor for temperature measurement, Acta Physica Polonica A, 2015, 127, 730-733.

[31] Miluski P., Kochanowicz M., Zmojda J., Spectroscopic investigation of organic co-doped PMMA for optical fiber technology, Journal Of Optoelectronics And Advanced Materials, 2017, 19(56), 379-383. 